\title{
Inventarisasi organisme avertebrata terumbu karang di perairan Tanjung Dehegila Kabupaten Pulau Morotai
}

\author{
(Avertebrata organism inventory of coral reef in Tanjung Dehegila District of \\ Morotai Island)
}

\author{
Djainudin Alwi ${ }^{{ }^{*}}$, Sandra Hi. Muhammad ${ }^{2}$ dan Sukirno Bisi ${ }^{3}$ \\ Program Studi Ilmu Kelautan, FPIK-UNIPAS, Morotai \\ *email.djainudinalwi@gmail.com
}

\begin{abstract}
Morotai Island District is one of the areas that have abundant marine resources potential, especially fish species, as well various marine life such as sea cucumbers, lobsters and various types of mollusca that live in association with coral reefs. In terms of ecological aspects, some types of aveteberata organisms have a role as bioindicator for coral health while from economic aspect can be used food and medicine and of course have very high selling value. Data and information on the potential of non-fish marine resources such as coral reef invert organisms is still very minimal by it is necessary to conduct a scientific study of the existence of these organisms. The purpose of this study is to know the composition of species and to know the diversity of species, index dominance, uniformity index and density of coral reef invertebrate organisms. The study was conducted from May to September 2017, located in Cape Dehegila, Morotai Island District. Data retrieval method used is belt transect method (belt transect). The results showed that the composition of invertebrate species found in the study sites consisted of station many as 20 types and 54 individuals, station II as many as 11 species and 23 individuals, while at station III as many as 19 species and 45 individuals. Result of analysis of diversity of type of avertebrata in research location high classified, dominance index at all three stations is low. Meanwhile, the results of uniformity index analysis are high category. While the result of density type analysis of invertebrate organism at research location represented by lincikia laevigata from phylum Ehinodermata.
\end{abstract}

Keywords: inventory, averetebrarta organism, coral reef.

\begin{abstract}
ABSTRAK
Kabupaten Pulau Morotai merupakan salah satu wilayah yang memiliki potensi sumberdaya laut yang cukup melimpah, terutama jenis-jenis ikan, serta berbagai biota laut seperti, teripang, lobster dan berbagai jenis moluska yang hidup berasosiasi dengan terumbu karang. Ditinjau dari aspek ekologi beberapa jenis organisme aveteberata memiliki peran sebagai bio-indikator bagi kesehatan karang sedangkan dari aspek ekonomidapat dimanfaatkan sebagai bahan makanan maupun obat-obatan dan tentunya memiliki nilai jual yang sangat tinggi. Data dan informasi mengenai potensi sumberdaya laut non ikan seperti organisme avertebrata terumbu karang masih sangat minim olehnya itu perlu dilakukan kajian ilmiah mengenai keberadaan
\end{abstract}


organisme tersebut. Tujuan penelitian ini adalah mengetahui komposisi jenis serta mengetahui keanekaragaman jenis, indeks dominasi, indeks keseragaman dan kepadatan jenis dari organisme avertebrata terumbu karang. Penelitian ini dilaksanakan pada bulan Mei sampai pada bulan September 2017yang berlokasi di Tanjung Dehegila Kabupaten Pulau Morotai. Metode pengambilan data yang digunakan yaitu metode transek sabuk(belt transect). Hasil penelitian menunjukan bahwa komposisi jenis avertebrata yang ditemukan pada lokasi penelitian terdiri dari; stasiun I sebanyak 20 jenis dan 54 individu, stasiun II sebanyak 11 jenis dan 23 individu, sementara pada stasiun III sebanyak 19 jenis dan 45 individu. Hasil analisis keanekaragaman jenis avertebrta dilokasi penelitian tergolong tinggi, Indeks dominansi pada ketiga stasiun tergolong rendah. Sementara itu hasil analisis indeks keseragamantermasuk kategori tinggi. Sedangkan hasil analisis kepadatan jenis organisme avertebrata dilokasi penelitian di wakili oleh jenis lincikia laevigata dari Filum Ehinodermata.

Kata kunci: inventarisasi, organisme averetebrarta, terumbu karang.

\section{Pendahuluan}

Kabupaten Pulau Morotai merupakan wilayah pulau yang paling utara di Kawasan Timur Indonesia (KTI) yang berada tepat di sebelah Pulau Halmahera sebagai bagian dari Provinsi Maluku Utara. Secara administratif luas wilayah Pulau Morotai sebesar $1.800 \mathrm{~km}^{2}$ dikelilingi 33 pulau-pulau kecil yang memiliki potensi sumberdaya laut yang cukup melimpah. (Pahlevi, 2011). Nontji (2002) mengemukakan bahwa salah satu dari potensi sumberdaya hayati laut yang tidak ternilai harganya dari segi ekonomi dan ekologi adalah terumbu karang. Dari segi estetika terumbu karang yang masih utuh menampilkan pemandangan yang sangat indah, jarang dapat ditandingi oleh ekosistem lain. Terumbu karang merupakan habitat (tempat hidup) berbagai biota bernilai ekonomi tinggi, seperti ikan, teripang, lobster, rumput laut, kima, kerang, siput, dan bulu babi. Terumbu karang juga merupakan ekosistem bawah laut yang indah, sehingga menjadi potensi wisata yang besar. Umumnya ekosistem terumbu karang merupakan bagian dari ekosistem laut yang penting karena menjadi sumber kehidupan bagi beraneka ragam biota laut.Hal senada juga dikemukakan oleh (Lalamentik, 1991) bahwa terumbu karang merupakan habitat berbagai organisme laut. Diperkirakan lebih dari 3.000 spesies dapat dijumpai pada terumbu karang yang ada di Asia Tenggara. Terumbu karang lebih banyak terdapat hewan avertebrata, beberapa jenis ikan seperti ikan badut (Clown Fish) dan kepe-kepe menghabiskan seluruh waktunya di terumbu karang.

Dalam kehidupan sehari hari manusia lebih banyak menemukan hewan vertebrata, sementara jumlah spesies hewan vertebrata hanya 5\% dan selebihnya merupakan avertebrata. Avertebrata merupakan hewan yang jenisnya tidak memiliki tulang punggung antar ruas-ruas tulang belakang yang berlainan dengan hewan vertebrata yang memiliki tulang belakang. Dalam pembagianya, hewan avertebrata di bagi menjadi beberapa golongan yaitu filum Protozoa, Porifera, Coelenterata, Platyhelmintes, Nemathelmintes, Annelida, Mollusca, Arthopoda, dan Echinordemata (Suwignyo (2005). Dewasa ini permintaan akan organisme avertebrata terumbu 
karang semakin hari terus meningkat terutama yang bernilai ekonomi tinggi seperti teripang, kima dan lobster, menyebabkan pemanfaatan oleh masyarakat semakin meningkat pula, jika pemanfaatannya tidak dilakukan secara berkelanjutan atau kurangnya perhatian dari pemerintah, maka hewan ini akan mengalami degradasi atau bahkan kepunahan.

Sementara itu data dan informasi mengenai potensi sumberdaya laut non ikan seperti organisme avertebrata terumbu karang masih sangat minim. Olehnya itu perlu dilakukan kajian ilmiah mengenai keberadaan organisme avertebrata terumbu karang di Perairan Tanjung Dehegila Kabupaten Pulau Morotai yang bertujuan memberikan informasi mengenai komposisi jenis serta manfaat secara ekologis dan ekonomis dari organisme avertebrata terumbu karang yang berada dilokasi penelitian, sehingga dapat dijadikan sebagai referensi bagi stakeholder yang berkepentingan dalam menentukan kebijakan pengelolaan sumberdaya kelautan dan perikanan di Kabupaten Pulau Morotai.

\section{Metodologi penelitian}

\subsection{Waktu dan tempat penelitian}

Penelitian ini dilaksanakan pada bulan Mei sampai September 2017 yang berlokasi di Tanjung Dehegila, Kecamatan Morotai Selatan Kabupaten Pulau Morotai dengan posisi geografis yaitu stasiun I. N. 01 ${ }^{\circ} 54.60^{\prime \prime}$-E. $128^{\circ} 15^{\prime} 33.77 "$, stasiun II.

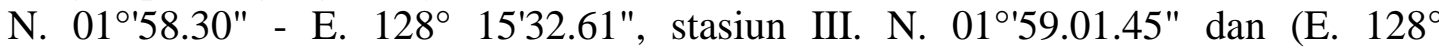
$\left.15^{\prime} 38.32 "\right)$.

\subsection{Prosedur penelitian}

Teknik pengumpulan data dilakukan dengan cara observasi (pengamatan) langsung terhadap objek penelitian. Data primer mencakup pengamatan dan pengukuran terhadap objek penelitian berupa jenis dan jumlah individu dari organisme avertebrata penghuni ekosistem terumbu karang. Sedangkan data sekunder diperoleh berdasarkan studi kepustakaan tentang jenis-jenis avertebrata, ekosistem terumbu karang, parameter lingkungan yang berpengaruh serta apa saja yang masih terkait dalam penelitian ini. Pengambilan data dalam penelitian ini dibagi dalam 2 (dua) tahap yaitu :

\subsubsection{Survei awal}

Sebelum kegiatan pengambilan data dimulai sehari sebelumnya dilakukan survei awal untuk menentukan penentuan stasiun. Survei dilakukan dengan menggunakan metode Manta Tow. Teknik dilakukan dengan cara berenang bebas dipermukaan dan menyisir areal terumbu karang guna mengetahui keberadaan organisme avertebrata serta melihat secara visual kondisi terumbu karang untuk dijadikan sebagai stasiun pengamatan. Metode ini sangat cocok untuk memantau daerah terumbu karang yang luas dalam waktu yang pendek, biasanya untuk melihat kerusakan akibat adanya badai topan, bleaching, daerah bekas bom dan hewan Acanthaster planci (bulu seribu). Teknik ini juga sering digunakan untuk mendapatkan daerah yang mewakili untuk di survei lebih lanjut dan lebih teliti 
dengan metode transek sabuk (belt transect) dan sejenisnya. Dari hasil survei awal yang dilakukan ditentukan sebanyak 3 stasiun. Pembagian stasiun pengamatan ini dimaksudkan agar semua lokasi penelitian dapat terwakili sehingga menghindari terjadinya error data selain itu juga dapat diperoleh data pembanding antara stasiun penelitian.

\subsubsection{Pengumpulan data}

Pengumpulan data dalam penelitian ini menggunakan metode Transek Sabuk (belt transect) dimana metode ini digunakan untuk menggambarkan kondisi populasi berbagai organisme atau biota avertebrata yang berasosiasi dengan terumbu karang. (Johan, 2009). Panjang transek yang digunakan adalahh $50 \mathrm{~m}$ dan lebar $5 \mathrm{~m}$, dengan pembagian 2.5 samping kanan dan 2.5 samping kiri. Penempatan transek dilakukan secara horizontal sejajar dengan garis pantai, menyesuaikan kontur dimana terdapat terumbu karang dengan menggunakan gerakan zig-zag (gerakan menyilang) mengikuti panjang dan lebar transek. Gerakan ini dimaksudkan agar semua areal transek tidak terlewati dan dapat terkaver dengan baik (Gambar 1). Organisme avertebrata yang ditemukan dalam areal transek dicatat jumlah individu dan jenisnya pada tabel pengambilan data dan untuk keperluan identifikasi semua jenis avertebrata yang ditemukan dan diambil gambarnya menggunakan kamera underwater dengan menggunakan panduan buku identifikasi avertebrata (Colin dan Arneson 1995) dan (Setiawan 2010). Sebagai data pendukung diukur pula parameter lingkungan seperti, suhu, salinitas, kecepatan arus dan $\mathrm{pH}$ air.

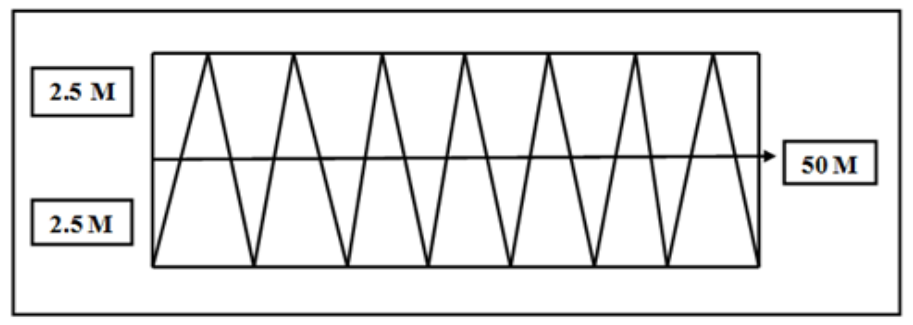

Gambar 1. Metode transek sabuk (belt transect)

\subsection{Analisis data}

\subsubsection{Komposisi jenis avetebrata}

Data hasil pengamatan jenis dan jumlah individu organisme avertebrata yang ditemukan dilokasi penelitian di sajikan dalam bentuk tabel atau grafik berdasarkan stasiun pengamatan dengan menggunakan aplikasi excel 2007 kemudian dijelaskan secara deskriptif.

\subsubsection{Struktur komunitas.}

Analisis data keanekaragaman jenis, indeks dominasi, indeks keseragaman dan kepadatan jenis avertebrata terumbu karang yang ditemukan dilokasi penelitian menggunakan formula sebagai berikut : 


\section{1) Keanekaragaman jenis}

Keanekaragaman jenis dapat di katakan sebagai indikasi banyaknya jenis organisme avertebrata dan bagaimana penyebaran jumlah individu pada setiap jenis dan lokasi sampling. Keanekaragaman dihitung dengan menggunakan jumlah Shannon-Winner

(Odum, sebagai berikut:

Keterangan:

$$
H^{s}=-\sum_{i=1}^{s} \mathrm{Pi} \ln \mathrm{Pi}_{\mathrm{i}}
$$

$\mathrm{H}^{\prime} \quad$ : Indeks keanekaragaman Jenis

$\mathrm{Pi} \quad: \mathrm{ni} / \mathrm{N}$

ni : Jumlah individu jenis ke-i

$\mathrm{N}$ : Jumlah total individu

$\mathrm{S}$ : Jumlah total spesies Avertebrata

Keanekaragaman jenis $\left(\mathrm{H}^{\prime}\right)$ terdiri dari beberapa kriteria, yaitu:

$\mathrm{H}^{\prime}>3,0=$ menunjukkan keanekaragaman sangat tinggi

$\mathrm{H}^{\prime} 1,6-3,0=$ menunjukkan keanekaragaman tinggi

$\mathrm{H}^{\prime}$ 1,0 1,5 = menunjukkan keanekaragaman sedang

$\mathrm{H}^{\prime}<1 \quad=$ menunjukkan keanekaragaman rendah

\section{2) Indeks dominansi}

Untuk menghitung indeks dominasi digunakan rumus (Simpson, 1949 dalam Odum., 1971) sebagai berikut:

Keterangan:

$$
c=\sum_{i=1}^{s}(\mathrm{P} i)^{2}
$$

$\mathrm{C}$ : Indeks dominasi

Pi : Jumlah individu spesies ke-i

$\mathrm{S}$ : Jumlah total spesies

Nilai indeks dominansi dikelompokan dalam tiga kriteria, yaitu :

$0<\mathrm{C} \leq 0.5=$ Dominansi rendah

$0.5<\mathrm{C} \leq 0.7=$ Dominansi sedang

$0.75<\mathrm{C} \leq 1=$ Dominansi tinggi

\section{3) Indeks keseragaman}

Keseragaman dapat dikatakan sebagai keseimbangan, yaitu komposisi individu tiap jenis yang terdapat dalam suatu komonitas. Keseragaman jenis dapat dihitung dengan menggunakan rumus Evennes (Odum., 1993) sebagai berikut:

$$
E=\frac{H^{\prime}}{H_{\max }}
$$


Keterangan:

E : indeks keseragaman

$\mathrm{H}^{\prime} \quad$ : indeks keanekaragaman

$\mathrm{H}$ max : Keanekaragaman spesies maksimum

Dimana :

$E<0,4 \quad$ : Tingkat keseragaman populasi kecil

$0,4<E<0,6 \quad$ : Tingkat keseragaman populasi sedang

$E>0,6 \quad$ : Tingkatan keseragaman populasi besar

\section{4) Kepadatan jenis}

Kepadatan jenis adalah jumlah individu per satuan luas. kepadatan masingmasing jenis pada setiap stasiun dihitung dengan menggunakan rumus menurut (Odum, 1971) yaitu :

$$
D i=\frac{n i}{A}
$$

Keterangan:

Di : Kepadatan Jenis

$\mathrm{Ni} \quad$ : Jumlah total Individu Jenis

A : Luas daerah yang disampling

\section{Hasil dan pembahasan}

\subsection{Komposisi jenis avertebrata berdasarkan stasiun pengamatan}

Organisme avertebrata yang ditemukan pada stasiun I (satu) berjumlah 20 jenis dan 55 individu (Gambar 2). Jumlah individu terbanyak terdapat pada jenis linckia laevigata sebanyak 24 individu, kemudian jenis Ophiomastix janualis sebanyak 5 individu, Theonella sp 4 individu, Lambis scorpius, Conusimperialis, Holothuria edulis, Tridacna squamosa masing-masing berjumlah 2 individu sedangkan jenis yang lain hanya ditemukan masing-masing 1 jenis yakni Dactylia sp, Trochus nilocitus, Oxycomanthus bennatti, Colometra, Cerithium alucho, Hyotssa hyotis, Periglypyta, Choriaster granulatus, Oceanapia sp, Linckia guildingi, Pearsonothuria graffei, pinctada maxima, thelenota anax.

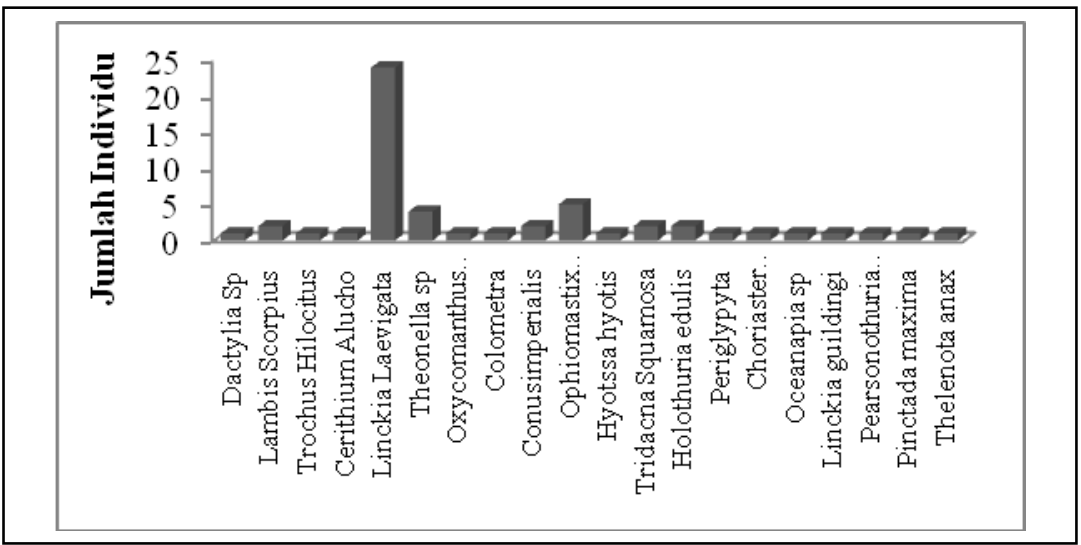

Gambar 2. Diagram jumlah dan jenis avertebrata pada stasiun I 
Stasiun II terlihat bahwa organisme avertebrata yang ditemukan sebanyak 11 jenis dengan jumlah total 23individu. Jenis Linckia laevigata,Tridacna derasa dan Tridacna squamosamerupakan jenis yang paling banyak ditemukan yakni masingmasing berjumlah 4 individu, selanjutnya Echinothris calamaris 3 individu sementara itu Ophiomastix janualis sebanyak 2 individu dan yang paling sedikit ditemukan pada stasiun ini ialah jenis Panulirus versicolor, Conus aulicus, Trochus nilocitus, Diadema savignyi, Tridacna squamosa dan Pleurobranchus grandis masing-masing 1 individu (Gambar 14).

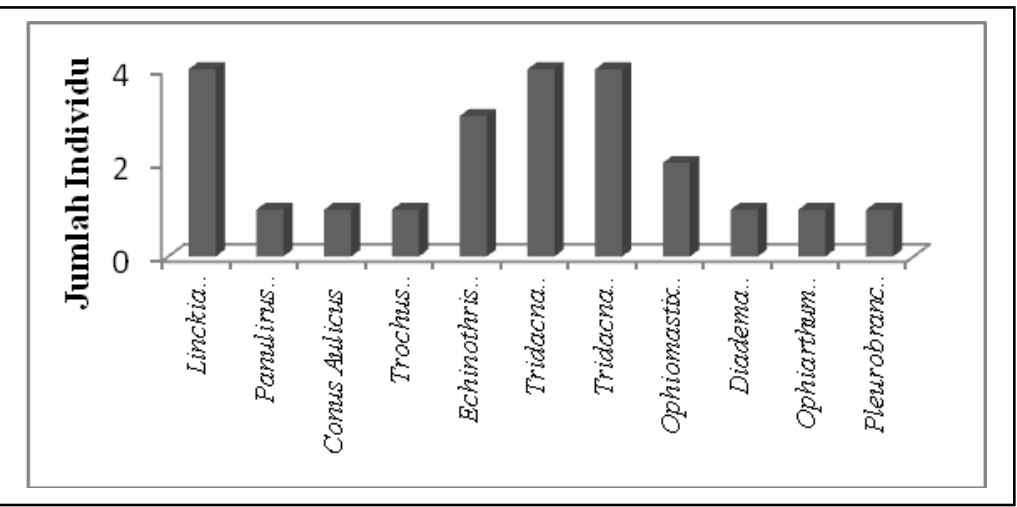

Gambar 3. Diagram jumlah dan jenis avertebrata pada stasiun II

Jumlah individu terbanyak masih didominasi oleh jenis Linckia laevigata dengan 18 individu kemudian terbanyak kedua diwakili oleh jenis Acanthella sp dan Spirobranchus gigantheus masing-masing 4 individu, dan jenis Coriacela nigra, Actinopyga palauensis, dan Trochus niloticus masing-masing 2 Individu, sedangkan jumlah individu terendah dari jenis Conus marmoreus, Fryaria ruppeli, Echinothris calamaris, Echinometra mathaei, Phyllidia sp, Aaptos chromis, Xestospongia testudinaria, Kallypilidion fascigera, Tridacna squamosa, Acanthaster planci,Terrebellidae. dan Chromodoris kunei masing-masing 1 individu (Gambar 3). Sementara itu secara keseluruhan oraganisme avertebrata yang ditemukan pada stasiun III terdapat 19 jenis dengan jumlah sebanyak 45 individu

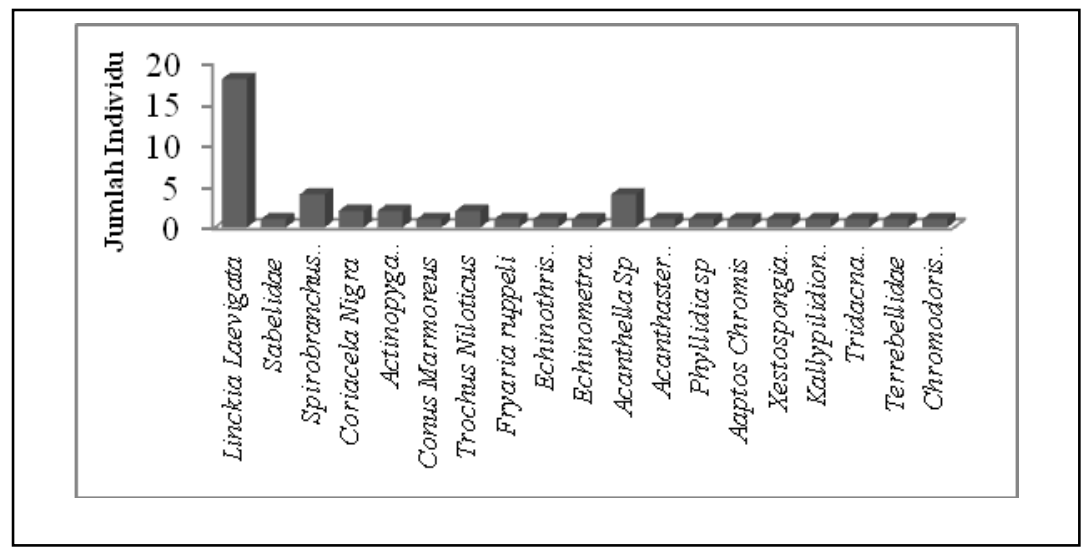

Gambar 4. Diagram jumlah dan jenis avertebrata pada stasiun III 
Jumlah jenis dan jumlah individu organisme avertebrata yang ditemukan pada ke 3 stasiun pengamatan cukup bervariasi (Gambar 2,3 dan 4). Oganisme avertebrata yang paling banyak ditemukan yaitu pada stasiun 1 sebanyak 20 jenis dengan jumlah total 55 individu. Sementara itu terbanyak kedua ditemukan pada stasiun III dengan jumlah jenis 19, dengan total individu sebanyak 45 sedangkan stasiun I dengan 11 jenis dan 23 jumlah individu. Perbedaan jumlah jenis dan individu organisme avertebrata dari ke tiga stasiun pengamatan ini kemungkinan disebabkan oleh kesesuain habitat yang ditempati oleh organisme avetebrata yakni ekosistem terumbu karang. Keberadaan berbagai organisme avertebrata sangat bergantung pada terumbu karang sebagai habitatnya jika terumbu karang dalam kondisi yang baik maka semakin banyak organisme yang menempati habitat tersebut. Hal ini sejalan dengan pendapat Yuliana dan Asriyana (2012) bahwa tingginya produktivitas primer di ekosistem terumbu karang, bisa mencapai $5000 \mathrm{gC} / \mathrm{m} 2 /$ tahun, memicu produktivitas sekunder yang tinggi, yang berarti komunitas makhluk hidup yang ada didalamnya sangat beraneka ragam dan tersedia dalam jumlah yang melimpah.

\subsection{Struktur komunitas organisme avertebrata}

Keanekaragaman spesies dapat di katakan sebagai indikasi banyaknya jenis organisme dan bagaimana penyebaran jumlah individu pada setiap jenis dan lokasi sampling (Odum, 1993). Secara umum berdasarkan hasil analisis (Gambar 5) terlihat bahwa indeks keanekaragaman jenis $\left(\mathrm{H}^{\prime}\right)$ organisme avertebrata yang di temukan dilokasi penelitian pada masing-masing stasiun penelitian termasuk pada kategori tinggi karena nilai keanekaragaman jenis $\left(\mathrm{H}^{\prime}\right)$ dari ketiga stasiun rata-rata sebesar $\mathrm{H}^{\prime}$ $=2.2474$. Tingginya indeks keanekaragaman jenis avertebrata yang hidup dilokasi penelitian dikarenakan habitat yang ditempati sudah sesuai dengan kehidupannya.

Selain itu organisme avertebrata yang berada dilokasi penelitian memiliki kompleksitas yang tinggi, dimana didalam komunitas selalu terjadi interaksi antar spesies. Sejalan dengan itu menurut Gustiarisane (2001) dalam Yulianti dkk,(2013) menyatakan apabila nilai keanekaragaman jenis dikatakan tinggi menunjukan bahwa keadaan ekologis pada suatu daerah mengalami tekanan yang rendah sehingga keragaman spesiesnya tinggi dengan sebaran individu tinggi dan kestabilan komunitas akan mengalami hal yang sama.

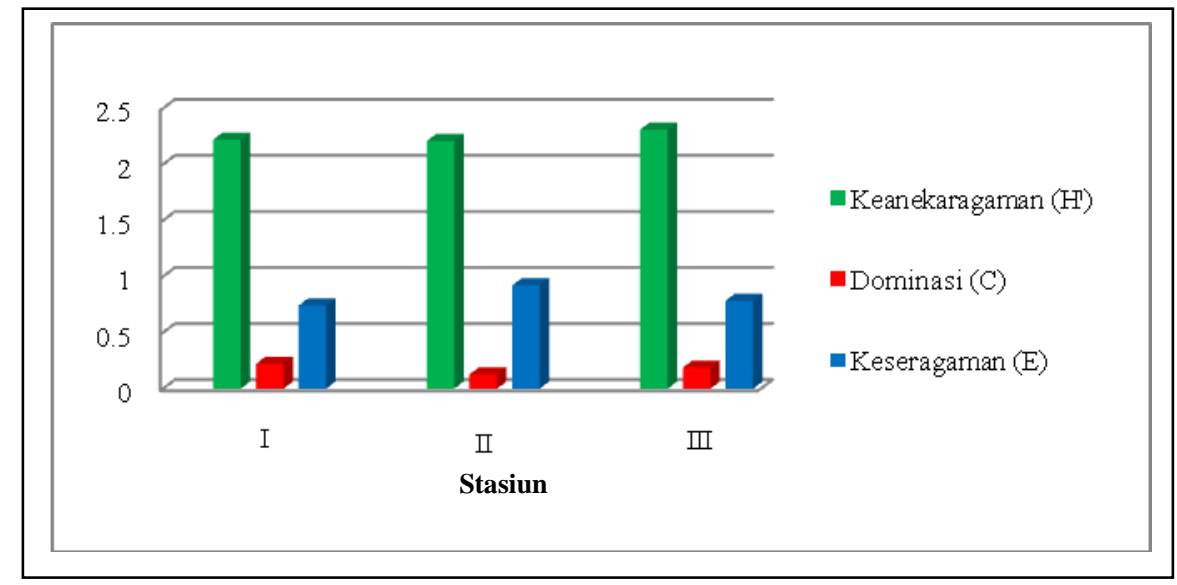

Gambar 5. Diagram Nilai Keanekaragaman Jenis, $\left(\mathrm{H}^{\prime}\right)$ indeks Dominasi (C)dan IndeksKeseragaman(E)Tiap Stasiun. 
Berdasarkan hasil analisis Indeks dominasi (C) organisme avertebrata yang ditemukan dilokasi penelitian pada masing-masing stasiun menunjukan bahwa dominasi tertinggi dari ketiga stasiun berada pada stasiun I dengan nilai $(\mathrm{C})=$ 0.2215 , dan stasiun III dengan nilai $(\mathrm{C})=0,1881$ sedangkan dominasi terendah berada pada stasiun II dengan nilai (C) =0,1267 (Gambar 5).

Tingginya nilai indeks dominasi pada stasiun I disebabkan karena terdapat salah-satu jenis avertebrata yakni jenis Lincikia laevigata yang paling mendominasi, sementara dominasi rendah pada 2 (dua) stasiun lainya lebih disebabkan kurangnya dominasi dari spesies tertentu. Dominasi jumlah individu dari jenis Linckia laevigata lebih di sebabkan oleh kemampuan adaptasi dari organisme jenis ini dibandingkan dengan organisme lain dalam mentoleransi perubahan lingkungan pada habitanya. Hal ini diperkuat oleh pendapat Yuliana dan Asriyana (2012), bahwa kehadiran suatu kelompok organisme pada suatu habitat dipengaruhi oleh beberapa parameter lingkungan seperti, suhu, kecepatan arus, salinitas, $\mathrm{pH}$ dan parameter fisik lainya.

Rendahnya Indeks dominasi (C) avertebrata dilokasi penelitian disebabkan karena terjadi peledakan populasi salah satu jenis, karena jenis yang lain tidak mampu bersaing dalam hal, ruang maupun makanan. Selain faktor lingkungan yang berpengaruh terhadap keberadaan organisme avertebrata dilokasi penelitian, faktor manusia juga menjadi pemicu terjadi ketidakseimbangan dalam ekosistem, dominasi jenis linckia laevigata di semua stasiun pengamatan. Namun jenis yang lain dari filum moluska seperti (Pinctada maxima, Lambis scorpius, Trochus hilocitus, Tridacna squamosa )terlihat sangat minim jumlah individunya dari semua stasiun pengamatan, hal ini disebabkan karena banyak masyarakat disekitar lokasi penelitian memanfaatkan organisme ini untuk dijadikan bahan konsumsi sehingga keberadaan populasi organisme avertebrata khususnya yang memilki nilai ekonomis mengalami degradasi yang cukup signifikan.

Hasil Penelitian dari Allen dan Mc Kenna (2001) dalam Nadiarti et al. (2015) tentang identifikasi ikan dan organisme terumbu karang dimana terdapat 819 spesies ikan serta 541 spesies Moluska dari 103 Famili dan mengestimasikan bahwa jumlah total spesiesikan melebihi 900 spesies. Selain biota indikator, jumlah genus dan spesies ikan yang teramati di Pulau Sonit dansekitarnya cukup tinggi, namun kelimpahan setiap spesiesumumnya rendah. Sedangkan untuk moluska dan avertebrata lain jumlah maupun keanekaragaman tergolong rendah. Dugaan terjadinya pemanfaatan cukup intensif oleh masyarakat dan kemungkinan berlebih terhadap berbagai jenis ikan dan avertebrata berasosiasi dengan ekosistem terumbu karang.

Terumbu karang bukan merupakan sistem yang statis dan sederhana, melainkan suatu ekosistem yang dinamis dan kompleks. Berbagai jenis makhluk hidup yang ada di ekosistem terumbu karang saling berinteraksi satu sama lain, baik secara langsung maupun tidak langsung, membentuk suatu sistem kehidupan. Sistem kehidupan di terumbu karang dapat bertambah atau berkurang dimensinya akibat interaksi kompleks antara berbagai kekuatan biologis dan fisik. (Nybakken, 1986).

Keseragaman dapat dikatakan sebagai keseimbangan yaitu komposisi individu tiap jenis yang terdapat dalam suatu komunitas. Hasil analisis sebagaimana terlihat 
pada gambar 9 menunjukan keseragaman tertinggi berada pada stasiun II dengan nilai keseragaman $(E)=0.9211$ diikuti stasiun III dengan nilai keseragaman $(E)=0.7851$ sedangkan yang terendah berada pada stasiun I dengan nilai keseragaman $(\mathrm{E})=$ 0.7418 .

Secara umum hasil analisis indeks keseragaman yang diperoleh pada masingmasing stasiun penelitian tergolong tinggi karena nilai keseragaman yang diperoleh $(E)=>0.6$ (lihat kriteria keseragaman). Tingginya nilai keseragaman (E) organisme avertebrata yang ditemukan dilokasi penelitian mengindikasikan bahwa pembagian individu pada masing-masing spesies merata pada suatu komunitas dan tidak ada jenis tertentu yang mendominasi dan sebaliknya jika indeks keseragaman semakin kecil maka keseragaman suatu populasi akan semakin kecil pula (Krebs, 1985 dalam Hutauruk, 2009).

\subsection{Kepadatan Jenis (D)}

Kepadatan jenis ialah jumlah individu perjenis dibagi dengan luas areal yang di sampling. Hasil analisis kepadatan jenis pada stasiun I terlihat bahwa (Gambar 6) oraganisme avertebrata yang memilki kepadatan tertinggi di tempati oleh jenis Lincikia laevigata dengan nilai kepadatan sebesar $0.096\left(\mathrm{ind} / \mathrm{m}^{2}\right)$, diikuti oleh jenis Ophiomastix janualissebesar $0.02\left(\mathrm{ind} / \mathrm{m}^{2}\right)$, Theonella sp $0.016\left(\mathrm{ind} / \mathrm{m}^{2}\right)$. sementara itu jenis Lambis scorpius, Conusimperialis, Tridacna squamosa, Holothuria edulis masing-masing memiliki nilai kepadatan yang sama yaitu 0.008 (ind $/ \mathrm{m}^{2}$ ). Sedangkan kepadatan terrendah ditempati oleh jenis Dactylia sp, Trochus hilocitus, Cerithium alucho, Oxycomanthus bennatti, Colometra, Hyotssa hyotis, Periglypyta, Choriaster granulatus, Oceanapia sp, Linckia guildingi, Pearsonothuria graffei,Pinctada maxima, Thelenota anax dengan nilai kepadatan sebesar 0.004 (ind $/ \mathrm{m}^{2}$ ).

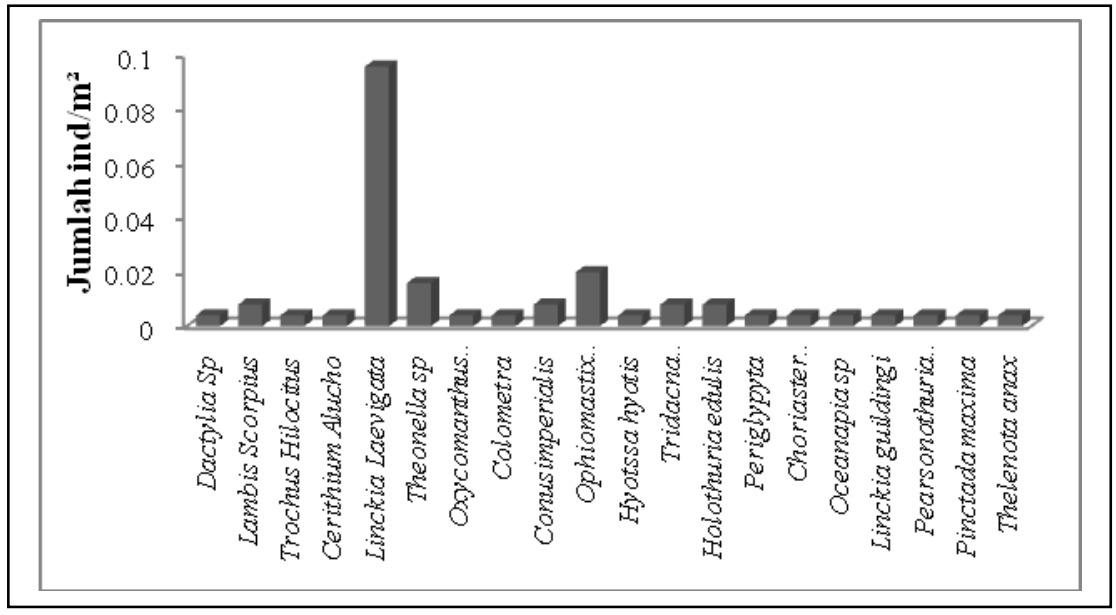

Gambar 6. Nilai Kepadatan Jenis (D) Pada Stasiun I 
Nilai kepadatan jenis pada stasiun II tertinggi di tempati oleh 3 (tiga) jenis organisme avertebrata yakni Linckia laevigata, Tridacna derasa, Tridacna squamosa dengan nilai kepadatan masing-masing sebesar $0.016\left(\mathrm{ind} / \mathrm{m}^{2}\right)$ diikuti oleh jenis Echinothris calamaris dan Ophiomastix janualis dengan nilai kepadatan sebesar 0.012 (ind $/ \mathrm{m}^{2}$ ) dan 0.08 (ind $/ \mathrm{m}^{2}$ ) (Gambar 7). Sedangkan nilai kepadatan terendah ditempati oleh jenis Panulirus versicolor, Conus aulicus, Trochus nilocitus, Diadema savignyi, Ophiarthum elegans, Pleurobranchus grandis dengan nilai kepadatan jenis sama yakni 0,004 (ind $/ \mathrm{m}^{2}$ ).

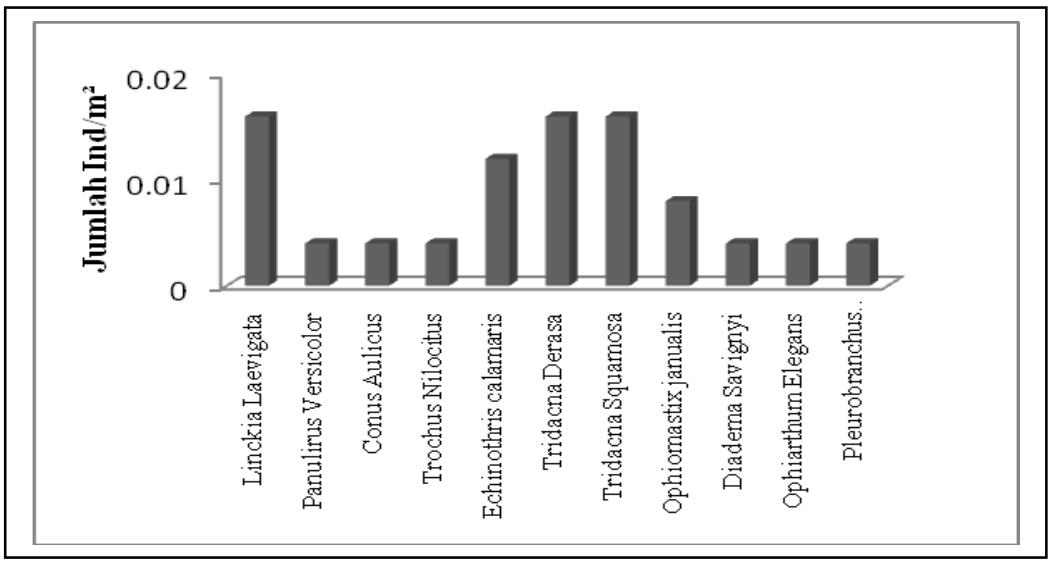

Gambar 7. Nilai Kepadatan Jenis (D) Pada Stasiun I

Berdasarkan hasil analisis nilai kepadatan (D) pada stasiun III (Gambar 8) organisme avertebrata yang paling banyak ditemukan masih ditempati oleh jenis Linckia laevigata dengan nilai kepadatan sebesar $0.072\left(\mathrm{ind} / \mathrm{m}^{2}\right)$ lalu disusul olehSpirobranchus gigantheus dan Acanthella sp dengan nilai 0.016 (ind $/ \mathrm{m}^{2}$ ), untuk Coriacela nigra, Actinopyga palauensis dan Trochus niloticus dengan nilai kepadatan masing-masing sebesar 0.008 (ind $/ \mathrm{m}^{2}$ ) sedangkan yang paling terendah yaitu jenis Sabelidae, Conus marmoreus, Fryaria ruppeli, Echinothris calamaris, Echinometra mathaei, Acanthaster planci, Phyllidia sp, Aaptos chromis, Xestospongia testudinaria, Kallypilidion fascigera, Tridacna squamosa, Terrebellidae, Chromodoris kunei dengan nilai kepadatan rata-rata $0.004\left(\mathrm{ind} / \mathrm{m}^{2}\right)$.

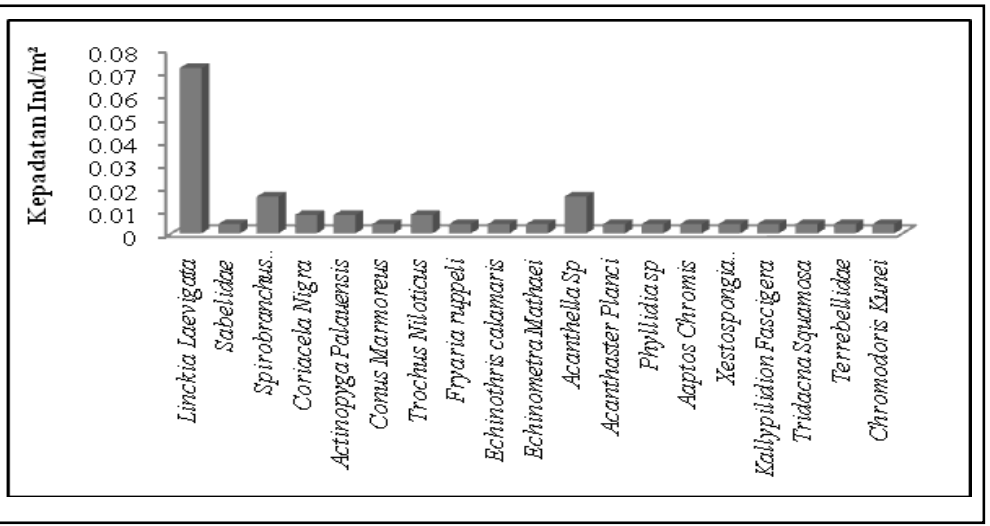

Gambar 8. Nilai Kepadatan Jenis (D) pada Stasiun III

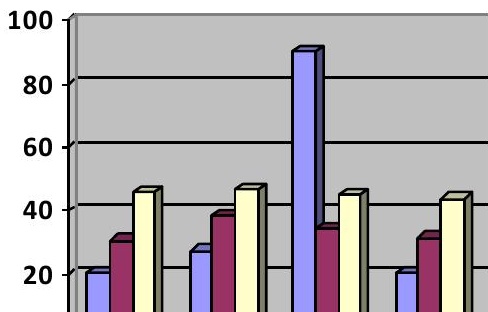


Tingginya nilai kepadatan yang diperoleh jenis tertentu disebabkan karena habitat yang ditempati dapat menunjang bagi kehidupan organisme tersebut. Berdasarkan hasil pengamatan di lokasi penelitian pada stasiun I secara visual presentasi tutupan karang hidup di perkirakan mencapai $85 \%$ sementara pada stasiun II hanya berkisar 50\% sedangkan pada stasiun III mencapai $75 \%$ Selain itu tingginya nilai kepadatan dari jenis Linckia laevigata dari ketiga stasiun penelitian ini juga disebabkan karena jenis ini tidak memiliki nilai ekonomis sehingga tidak diambil atau di konsumsi oleh masyarakat disekitar, dengan demikian maka populasi dari jenis Linckia laevigata ini terus meningkat.

\subsection{Hasil Pengukuran Parameter Lingkungan}

Hasil pengukuran parameter lingkungan di tiga stasiun pengamatan tidak ada perbedaan yang signifikan, salinitas yang diukur dari 3 stasiun sama yakni 35\%o, suhu berkisar antara $27^{\circ} \mathrm{C}-29^{\circ} \mathrm{C}$ dan kecepatan arus $0.03(\mathrm{~m} / \mathrm{s})-0.14(\mathrm{~m} / \mathrm{s})$ sedangkan $\mathrm{pH}$ berada pada kisaran 7,4 - 7.5 (selengkapnya dapat di lihat pada tabel 1). Dari data tersebut dapat di jelaskan bahwa parameter lingkungan yang berada di lokasi penelitian masih pada batas optimum untuk perkembangan dalam pertumbuhan berbagai makhluk hidup terutama organisme avertebrata penghuni terumbu karang.

Tabel 1. Hasil pengukuran parameter lingkungan dilokasi penelitian

\begin{tabular}{cccccc}
\hline No & Stasiun & Salinitas & Suhu & pH & Kec. Arus (m/s) \\
\hline 1 & I & $35 \%$ o & $28^{\circ} \mathrm{C}$ & 7.4 & 0.03 \\
\hline 2 & II & $35 \%$ o & $29^{\circ} \mathrm{C}$ & 7.4 & 0.14 \\
\hline 3 & III & $35 \% 0$ & $27^{\circ} \mathrm{C}$ & 7.5 & 0.09 \\
\hline
\end{tabular}

Nybakken, (1992) dalam Yuliana dan Asriyani (2012) berpendapat bahwa terumbu karang sebagai habitat avertebrata dapat berkembang dengan baik pada perairan yang bersih, bebas sedimen, dan polusi, perairan yang masih bisa tembus cahaya (fotik), ada benih (planula), adanya arus, substrat, kekeruhan rendah, suhu yang paling baik sekitar $18-40{ }^{\circ} \mathrm{C}$ dan suhu yang paling optimal adalah $23-25{ }^{\circ} \mathrm{C}$, dan salinitas antara $30-36 \%$.

\section{KESIMPULAN}

Hasil penelitian dapat disimpulkan beberapa hal sebagai berikut :

1. Komposisi avertebrata terumbu karang yang ditemukan di lokasi penelitian yakni pada stasiun I sebanyak 20 jenis dan 54 individu, sementara itu pada stasiun II sebanyak 11 jenis dan 23 individu, sedangkan pada stasiun III sebanyak 19 jenis dan 45 individu. 
2. Keanekaragaman jenis avertebrata pada lokasi penelitian kategori tinggi. Indeks dominasi avertebrata kategori rendah. Hasil analisis indeks keseragaman kategori tinggi. Sedangkan hasil analisis kepadatan (D) pada semua stasiun penelitian ditempati oleh jenis Linckia laevigatadan yang tertinggi berada pada stasiun III nilai kepadatan sebesar $0.072\left(\mathrm{ind} / \mathrm{m}^{2}\right)$.

\section{Daftar Pustaka}

Colin, P.L., and C. Arneson. 1995. Tropical Pacific Invertebrates, A Field Guide to Marine Invertebrates Occurring on Tropical Coral Reefs, Seagrass Beds and Mangroves. Coral Reef Press, Beverly Hills, C.A., USA

Hutauruk L. E. 2009. Studi Keanekaragaman Echinodermata di Kawasan Perairan Pulau Rubiah Nanggroe Aceh.Skripsi.Universitas Sumatra Utara Medan

Insafitri, 2010 Keanekaragaman, Keseragaman Dan Dominasi Bivalvia Di Area Buangan Lumpur Lapindo Muara Sungai Porong. Jurnal kelautan, Volume 3 No.1. april 2010 ISSN: 1907-9931. Universitas trunojoyo. Hal. 54-59.

Johan, O. 2009. Metode Survei Terumbu Karang Indonesia. Disampaikan pada acara Training Course: Karakteristik Biologi Karang, tanggal 7-12 Juli 2003, yang diselenggarakan oleh PSK-UI dan Yayasan TERANGI, dan didukung oleh IOI-Indonesia.

Lalamentik, 1991. Analisis Aspek Ekologi Penataklolaan Ekosistem Terumbu karang. FPIK Unsrat Manado.

Nadiarti,. Tauhid U,.Yayu A., Nafie, Fajriani D. dan Inaku, (2015) Prosiding Simposium Nasional II Kelautan dan Perikanan 2015. Makassar, 5 Oktober 2015

Nontji, A. 2002. Laut Nusantara. Penerbit Djambatan Jakarta. 368 hal

Nybakken, 1986. Biology Laut Suatu Pendekatan Ekologis. Penerbit Gramedia Pustaka Utama Jakarta

Odum E P., 1971. Fundamental Of Ecology. Philadelphia London Toronto. W.B. Souders Company.

Odum. 1993. Dasar-dasar ekologi. Diterjemahkan oleh Samingan. Edisi ketiga. Gajah mada University. Yokyakarta.

Pahlevi Indra, 2011. Pengelolaan Pemerintahan Di Wilayah Perbatasan. Bagian Pertama. Hal 1 - 179. Peneliti Masalah Politik dan Pemerintahan Indonesia Di Bidang Pengkajian P3DI Setjen DPR RI.

Setiawan F, 2010. Panduan Lapangan Identifikasi Ikan Karang Dan Invertebrata Laut. Sulawesi Utara. Manado. (ID): Wildlife Concervation Society

Suwignyo, 2005. Avertebrata Air Jilid 1.Jakarta: Penebar Swadaya.

Yuliana dan Asriyana, 2012. Produktivitas Perairan. Penerbit PT Bumi Aksara. Jakarata. Hal 278.

Yulianti, E.L, Mangisela, B.F dan Tamannampo F.J. 2013. Kepadatan dan Keanekaragaman Fitoplankton di Perairan Sekitar Kawasan Reklamasi Pantai Manado. Jurnal Ilmiah Platax Vol.1:(3), ISSN: 2302-3589. FPIK UNSRAT Manado hal. 109-117. 